\title{
Caracterização do sistema de produção em propriedades leiteiras de economia familiar em Presidente Olegário - MG: Fase Recria de Fêmeas
}

\author{
[Characterization of heifers rearing in family owned dairy farms in \\ Presidente Olegário - Minas Gerais]
}

\section{"Artigo Científico/Scientific Article"}

\author{
José dos Reis Pereira ${ }^{1}$, Gercílio Alves de Almeida Júnior ${ }^{2}$, Marcos Aurélio Lopes ${ }^{3 *}$, \\ Juliana Aparecida Vieira ${ }^{4}$, Alessandro Botelho Pereira ${ }^{5}$
}

\author{
${ }^{1}$ Empresa de Assistência Técnica e Extensão Rural, EMATER, Presidente Olegário-MG, Brasil. \\ ${ }^{2}$ Departamento de Zootecnia, Universidade Federal do Espírito Santo, Alegre-ES, Brasil. \\ ${ }^{3}$ Departamento de Medicina Veterinária, Universidade Federal de Lavras, Lavras-MG, Brasil. \\ ${ }^{4}$ Departamento de Zootecnia, Universidade Federal de Lavras, Lavras-MG, Brasil. \\ ${ }^{5}$ Empresa de Pesquisa Agropecuária de Minas Gerais, EPAMIG, Lavras-MG, Brasil. \\ *Autor para correspondência/Corresponding author: E-mail: malopes@ dmv.ufla.br
}

\begin{abstract}
Resumo
Objetivou-se, com este trabalho, caracterizar propriedades produtoras de leite, em regime de economia familiar, no que diz respeito a aspectos relacionados à recria de fêmeas bovinas leiteiras. Os dados utilizados foram provenientes de 12 propriedades produtoras de leite, localizadas na região Noroeste de Minas Gerais, no município de Presidente Olegário, na comunidade de Cachoeirinha/Boa Vista; no período entre maio e junho de 2016. Após a coleta, os dados foram cadastrados em planilhas do software Sphinx ${ }^{\circledR}$ e realizado o agrupamento das respostas por meio de sua categorização e frequência. Os dados das propriedades avaliadas evidenciaram que a baixa escolaridade, predomínio de mão de obra familiar e baixa participação de vacas em lactação nos plantéis são características comuns aos produtores. Foram identificadas diversas deficiências que se iniciam na desmama das bezerras e perpassam todo o período compreendido até a primeira cobertura das novilhas. A maioria dos produtores faz oferta suplementar de alimentos volumosos e concentrados, no entanto, a ausência de critérios técnicos para a divisão de lotes e alimentação das novilhas podem estar contribuindo significativamente para a perda de eficiência técnica e econômica nos plantéis avaliados. O peso e idade à primeira cobertura não são adequados ao padrão racial adotado nas propriedades, o que juntamente com a falta de correto manejo sanitário, pode vir a prejudicar a futura vida produtiva das fêmeas de reposição, assim como o desfrute e o melhoramento genético dos plantéis.
\end{abstract}

Palavras-chave: atividade leiteira; criação de novilhas; fêmeas de reposição.

\begin{abstract}
The objective of this study was to characterize family-owned dairy farms regarding aspects related to the rearing of heifers. The data came from 12 dairy farms, located in the Northwest region of Minas Gerais, in the municipality of Presidente Olegário, community of Cachoeirinha/Boa Vista; in the period between May and June 2016. After data collection, the data were recorded in Sphinx ${ }^{\circledR}$ software spreadsheets and the answers were grouped by their categorization and frequency. Data from the evaluated properties showed that the low scholarity, predominance of family labor, and low participation of cows in lactation in the herds are common characteristics of the farmers. Several deficiencies have been identified that begin with weaning of calves and continues through the whole period up to the heifers' first mating. Most of the farmers offer supplementary feeding of houghage and concentrates, however, the lack of technical criteria for the division of groups and feeding of heifers may be contributing significantly to the loss of technical and economic efficiency in the evaluated farms. Weight and age at first mating are not adequate to the breed standard adopted in the properties, which together with the lack of correct sanitary management, can damage the future productivity of the replacement females as well as the offtake and the genetic improvement of the herds.
\end{abstract}

Keywords: dairy business; heifer breeding; replacement females. 


\section{Introdução}

A recria de novilhas em rebanhos leiteiros é uma fase onerosa ao sistema de produção pois, durante esse período, o produtor despende muitos recursos que poderiam ser aplicados em outra área, como, por exemplo, aquisição de tecnologias, manejo de pastagem, melhoramento genético, etc. Além disso, a atividade de criação de animais de reposição ocupa uma área significativa do sistema de produção de leite (Santos e Lopes, 2014).

Em boa parte das propriedades leiteiras do Brasil o manejo de novilhas é a atividade que mais tem contribuído para o aumento dos custos de produção e queda na eficiência produtiva. Isso decorre da falta de atenção por parte do produtor a essa categoria animal tão importante em todo o processo produtivo. A origem da pouca relevância é devida ao fato de ser uma categoria ainda não produtiva e que, aparentemente, não traz benefícios diretos ao produtor. Este equívoco compromete a possibilidade do melhoramento contínuo do rebanho e, gualmente, a possibilidade de incrementar a produção leiteira, visto que as novilhas serão os animais de reposição (Viégas, 2010).

Esse problema se torna mais evidente em propriedades em regime de economia familiar onde, em geral, há grandes limitações no manejo das fêmeas de reposição nas fases de cria e recria, o que, comumente, resulta em baixo desempenho e até mesmo perdas de animais. $\mathrm{O}$ manejo e a alimentação na recria também podem impactar negativamente a atividade leiteira, deixando a reposição de matrizes cada vez mais onerosa e com dificuldades em encontrar animais de qualidade para agregar aos seus rebanhos.

O município de Presidente Olegário - MG, tem na bovinocultura de leite uma das suas principais atividades econômicas, geradora de emprego e renda, e que exerce, consequentemente, papel de grande importância social e ambiental. Dos produtores, $70 \%$ pertencem à agricultura familiar; a maioria são pequenos e médios produtores que produzem entre 100 a 300 litros de leite por dia e residem na propriedade, onde trabalham com sua família. A produção anual do município é de aproximadamente 52 milhões de litros, sendo que cinco milhões são destinados para produção de queijos (EMATER-MG, 2015). Possui um rebanho bovino efetivo de 131.589 cabeças e uma vasta área de pastagens, sendo 101.475 ha formadas e 57.498 de pastagens natu- rais. O sistema produtivo predominante é de produção de leite a pasto com animais mestiços (azebuados) (IBGE, 2014).

Considerando a importância do tema e a inexistência de literatura científica sobre o tema, retratando a região, objetivou-se, com este trabalho, realizar o diagnóstico de propriedades produtoras de leite, em regime de economia familiar, no que diz respeito a aspectos relacionados à recria das fêmeas bovinas.

\section{Material e Métodos}

Foram avaliadas 12 propriedades, produtoras de leite em regime de economia familiar, localizadas na região Noroeste de Minas, no município de Presidente Olegário, na comunidade de Cachoeirinha/Boa Vista no período entre maio e junho de 2016. O município conta com duas estações climáticas bem definidas, sendo uma denominada de período da seca (abril a setembro) e outra das águas (outubro a março), com pluviosidade média anual de $1.476 \mathrm{~mm}$ (ClimateData.Org, 2015).

Os produtores entrevistados foram selecionados aleatoriamente, independentemente do volume de leite comercializado ou do sistema de produção adotado. Para as entrevistas e diagnóstico utilizou-se um formulário semiestruturado, adaptado de Lopes et al. (2016). As questões foram divididas nos temas: cadastro do produtor e da propriedade, caracterização do rebanho e caracterização do sistema de produção de leite. Nesse último tópico incluia-se o sistema de produção, manejo nutricional, escrituração zootécnica, método de identificação dos animais e criação de bezerras. Na caracterização da recria das novilhas (desmama até a primeira cobrição ou inseminação), foram elaboradas questões que abordaram os cuidados com as novilhas, dieta, infraestrutura, controle sanitário, principais doenças e idade à primeira cobertura.

Os dados coletados foram cadastrados em planilhas do software Sphinx ${ }^{\circledR}$ e realizado o agrupamento das respostas de acordo com sua categoria no formulário de diagnóstico obedecendo à classe a qual pertencia, ou seja, o tema a qual pertenciam: se sanidade, caracterização do rebanho etc., para facilitar a velocidade de transcrição, interpretação e aplicação de ferramentas de estatísticas.

Os resultados foram comparados por meio 
de análises descritivas, utilizando o aplicativo MS Excel $^{\circledR}$, e agrupados em tabelas, objetivando melhor apresentação, comparação e discussão, segundo Lopes et al. (2004).

\section{Resultados e Discussão}

Constata-se a caracterização da pecuária em regime familiar ao se observar que $100 \%$ dos produtores residiam nas suas propriedades. Isso ressalta o relevante impacto econômico e social que esse tipo de atividade traz para a fixação do homem no campo, geração de renda e sucessão familiar para as próximas gerações de agricultorespecuaristas no Brasil (Tabela 1).

Tabela 1. Caracterização do produtor e das 12 propriedades estudadas do município de Presidente Olegário - MG, em maio e junho de 2016.

\begin{tabular}{|c|c|c|c|}
\hline \multirow{2}{*}{ Questão } & \multirow{2}{*}{ Averiguação } & \multicolumn{2}{|c|}{ Quantidade } \\
\hline & & Total & $\%$ \\
\hline Reside na propriedade ou não & Sim & 12 & 100,00 \\
\hline \multirow{6}{*}{ Escolaridade do proprietário responsável } & Pré-escola/creche & 2 & 16,67 \\
\hline & Fundamental incompleto & 8 & 66,67 \\
\hline & Fundamental completo & 1 & 8,33 \\
\hline & Superior incompleto & 1 & 8,33 \\
\hline & Menos de 5 & 3 & 25,00 \\
\hline & $6-10$ & 2 & 16.67 \\
\hline \multirow{4}{*}{$\begin{array}{l}\text { Há quanto tempo iniciou a atividade na pecuária } \\
\qquad(\text { anos })\end{array}$} & $11-15$ & 2 & 16,67 \\
\hline & $16-20$ & 2 & 16,67 \\
\hline & Acima de 21 & 3 & 25,00 \\
\hline & Herança & 3 & 25,00 \\
\hline \multirow{2}{*}{ A propriedade foi adquirida por } & Compra & 7 & 58,33 \\
\hline & Arrendamento & 2 & 16,67 \\
\hline \multirow{2}{*}{ Quantidade de funcionários permanentes } & 1 & 1 & 8,33 \\
\hline & Familiar & 11 & 91,67 \\
\hline \multirow{2}{*}{ Utiliza trabalhador temporário? } & Sim & 4 & 33,33 \\
\hline & Não & 8 & 66,67 \\
\hline \multirow{2}{*}{ Recebe assistência técnica? } & Sim & 3 & 25,00 \\
\hline & Não & 9 & 75,00 \\
\hline \multirow{2}{*}{ Qual a relação } & Estatal & 2 & 16,67 \\
\hline & Contratada & 1 & 8,33 \\
\hline \multirow{2}{*}{ Participa de algum projeto? } & Sim & 2 & 16,67 \\
\hline & Não & 10 & 83,33 \\
\hline \multirow{2}{*}{ Procura capacitação? } & Sim & 6 & 50,00 \\
\hline & Não & 6 & 50,00 \\
\hline \multirow{2}{*}{ Possui nascente de água? } & Sim & 6 & 50,00 \\
\hline & Não & 6 & 50,00 \\
\hline \multirow{2}{*}{$\begin{array}{l}\text { A fonte de água é perene } \\
\text { Há água suficiente para produção }\end{array}$} & Sim & 6 & 50,00 \\
\hline & Sim & 12 & 100,00 \\
\hline \multirow{2}{*}{ Faz tratamento de água? } & Sim & 1 & 8,33 \\
\hline & Não & 11 & 91,33 \\
\hline \multirow[t]{2}{*}{ Possui energia elétrica? } & Sim & 12 & 100,00 \\
\hline & Menos de 10 & 2 & 16,67 \\
\hline \multirow{3}{*}{ Área total para atividade leiteira (ha) } & De 10 a 19 & 5 & 41,67 \\
\hline & De 30 a 39 & 2 & 16,67 \\
\hline & Acima de 40 & 3 & 25,00 \\
\hline \multirow{2}{*}{ Possui pasto de aluguel? } & Sim & 4 & 33,33 \\
\hline & Não & 8 & 66,67 \\
\hline
\end{tabular}

Com relação à escolaridade 10 dos produtores possuíam até ensino fundamental incompleto; apenas um possuía ensino fundamental completo e um curso superior incompleto (Tabela 1). Soares et al. (2013) avaliaram o perfil de produtores de leite em cidades 
do Estado do Pará e observaram que entre os produtores com produção diária média até 53 litros, $30 \%$ eram analfabetos e $50 \%$ possuíam ensino fundamental. No estrato de 54 a 133 litros diários, $55 \%$ eram analfabetos e $5 \%$ possuíam curso superior. No estrato acima de 133 litros diários, $70 \%$ dos produtores apresentavam escolaridade em nível médio e $30 \%$ em nível superior. A baixa escolaridade por parte, principalmente dos pequeno e médios produtores, pode ser um entrave à adoção de tecnologias e profissionalização da pecuária de leite no Brasil. Borsanelli et al. (2014), em pesquisa realizada em diversos municípios do Estado de São Paulo, verificaram que a escolaridade e volume de produção têm associação com a percepção de risco de produtores de leite no uso de produtos veterinários, sendo os produtores com menores escolaridades e volumes de produção, mais vulneráveis aos riscos existentes no manejo sanitário do plantel e pior remunerados, principalmente no que diz respeito à qualidade do leite que, segundo Lopes et al. (2011), pode gerar um aumento na receita, pela bonificação praticada por muitos laticínios, que refletirá no aumento da rentabilidade.

A maioria dos produtores possuía até 20 anos de experiência na atividade leiteira. Em relação à aquisição da terra, sete a adquiriram por compra, três por herança e apenas dois trabalhavam em regime de arrendamento (Tabela 1). Considerando o tempo de experiência na atividade e a forma de aquisição da propriedade, talvez seja possível inferir que a sucessão familiar não esteja devidamente estabelecida entre os produtores de leite nas propriedades familiares avaliadas, o que por sua vez pode ser um reflexo de instabilidade econômica nesse tipo de atividade, não garantindo a prosperidade das sucessivas gerações. Em análise sobre sucessão hereditária em estabelecimentos rurais em agricultura familiar no Estado de Santa Catarina, Mello et al. (2003) relataram que 23\% dos agricultores adquiriram a terra por herança (da família do próprio agricultor ou do cônjuge), $45 \%$ por compra pela família e $32 \%$ por compra pelo próprio agricultor, corroborando com os resultados aqui encontrados.

Destaca-se que a maioria dos produtores não recebia nenhuma assistência técnica, o que coaduna com a percepção de que baixos níveis de escolaridade e volume de produção estão associados à falta de profissionalização e baixos desempenhos zootécnicos e econômicos na pecuária de leite familiar. Dentre os entrevistados, apenas três recebiam assistência técnica; destes, dois afirmaram que ela era estatal, sendo para um deles, contratada. Coelho (2009) ressaltou a importância em trabalhar com metas para técnicos nessas propriedades. Apenas dois produtores participavam de algum projeto relacionado à pecuária leiteira e tambétm apenas a metade afirmou procurar algum tipo de capacitação.

A água utilizada em metade das propriedades era proveniente de nascentes e apenas um produtor realizava tratamento de água. Em caracterização da produção leiteira no agreste do Estado de Pernambuco, Monteiro et al. (2007) observaram que apenas $12 \%$ das propriedades realizavam algum tratamento na água utilizada para higienização de instalações e equipamentos e $43,9 \%$ na água para consumo humano. Todos possuíam energia elétrica e a área total para atividade leiteira, em sete das propriedades, foi de até 19 ha, com apenas uma possuindo um funcionário permanente e em todas as demais a mão de obra permanente era estritamente familiar. Quanto a funcionários temporários, quatro dos produtores afirmaram fazer esse tipo de contratação durante algum período do ano (Tabela $1)$.

Os rebanhos das propriedades avaliadas eram predominantemente pequenos com apenas cinco dos produtores possuindo acima de 18 vacas em lactação e a mesma quantidade possuía acima de nove vacas secas, ou seja, em geral, uma baixa participação de vacas em lactação nos plantéis (Tabela 2).

Oliveira et al. (2001), avaliando propriedades na região de Viçosa, MG, encontraram percentuais de vacas em lactação em relação ao total de vacas do plantel, variando entre 53,1 a $87,5 \%$, com média de 70,6\%. Marcatti Neto et al. (2007), em diagnóstico da pecuária leiteira do município de Barroso, MG, encontraram o percentual médio de $63,1 \%$ de vacas em lactação em relação ao total de vacas e destacaram que esse percentual deveria ser em torno de $80 \%$ para que as propriedades apresentassem satisfatórios desempenhos ténicos e econômicos. Monteiro et al. (2007) encontraram $70,7 \%$ dos produtores possuindo plantel de até 50 animais e apenas $29,3 \%$ com mais de 50 animais, sendo que $43,9 \%$ das propriedades possuíam menos do que 25 vacas em lactação e 45,2\% das vacas tinham predominância de genética da raça holandesa. 
Quando considerado o rebanho total, também apenas cinco das propriedades avaliadas, neste trabalho, possuíam 56 ou mais animais. Em apenas quatro os animais eram da raça holandesa e também mestiços; nas demais, predominaram apenas mestiços, razão pela qual havia criação de machos em todas as propriedades (Tabela 2).

Tabela 2. Caracterização do rebanho e sistema de produção nas 12 propriedades estudadas do município de Presidente Olegário - MG, em maio e junho de 2016.

\begin{tabular}{|c|c|c|c|}
\hline \multirow{2}{*}{ Questão } & \multirow{2}{*}{ Averiguação } & \multicolumn{2}{|c|}{ Quantidade } \\
\hline & & Total & $\%$ \\
\hline \multirow{4}{*}{ Quantidade de vacas em lactação } & Menos de 8 & 2 & 16,67 \\
\hline & De 12 a 14 & 4 & 33,33 \\
\hline & De 15 a 17 & 1 & 8,33 \\
\hline & Acima de 18 & 5 & 41,67 \\
\hline \multirow{4}{*}{ Quantidade de vacas secas } & Menos de 3 & 2 & 16,67 \\
\hline & De 3 a 8 & 5 & 41,67 \\
\hline & De 9 a 14 & 4 & 33,33 \\
\hline & Acima de 15 & 1 & 8,33 \\
\hline \multirow{4}{*}{ Quantidade de fêmeas 0 a 12 meses } & Menos de 4 & 2 & 16,67 \\
\hline & De 4 a 7 & 3 & 25,00 \\
\hline & De 8 a 11 & 6 & 50,00 \\
\hline & Acima de 12 & 1 & 8,33 \\
\hline \multirow{3}{*}{ Quantidade de fêmeas acima de 12 meses } & Menos 4 & 6 & 50,00 \\
\hline & De 8 a 11 & 5 & 41,67 \\
\hline & Acima de 20 & 1 & 8,33 \\
\hline \multirow{4}{*}{ Quantidade de machos 0 a 12 meses } & Menos de 2 & 2 & 16,67 \\
\hline & De 2 a 5 & 5 & 41,67 \\
\hline & De 6 a 9 & 4 & 33,33 \\
\hline & Acima de 10 & 1 & 8,33 \\
\hline \multirow{3}{*}{ Quantidade de machos acima de 12 meses } & 0 & 7 & 58,33 \\
\hline & 1 & 4 & 33,33 \\
\hline & 9 & 1 & 8,33 \\
\hline \multirow{4}{*}{ Total de animais } & Menos de 24 & 2 & 16,67 \\
\hline & De 24 a 39 & 3 & 25,00 \\
\hline & De 40 a 55 & 2 & 16,67 \\
\hline & Acima de 56 & 5 & 41,67 \\
\hline \multirow{2}{*}{ Raça bovina predominante } & Holandesa/mestiços & 4 & 33,33 \\
\hline & Mestiços & 8 & 66,67 \\
\hline
\end{tabular}

Verifica-se na Tabela 3 que como sistema de produção, prevaleceu, na maioria das propriedades, o semiconfinamento, isto é, animais mantidos a pasto e suplementados no cocho; em quatro propriedades os animais eram mantidos a pasto durante todo o ano. Em metade, a média diária das vacas em lactação foi de 16 litros ou mais; e em apenas duas as vacas possuíam média abaixo de 9 litros. O volume diário de leite produzido e vendido, na metade das propriedades, foi de 250 litros ou mais; somente uma produzia e comercializava média abaixo de 50 litros. Apenas três das propriedades não possuíam "bezerro ao pé" durante ordenha e somente uma fazia ordenha de forma manual, sem ordenhadeira mecânica. No diagnóstico realizado por Marcatti Neto et al. (2007), apenas $10,5 \%$ dos produtores possuíam ordenhadeira mecânica, $16,7 \%$ produziam até 50 litros, $38,9 \%$ de 51 a 100 litros, $27,8 \%$ de 101 a 200 litros e 16,6\% acima de 200 litros por dia, sendo a produção diária média de 129 litros por propriedade e 6,6 litros por vaca. Monteiro et al. (2007) observaram que apenas $12,2 \%$ dos produtores adotavam ordenhadeira mecânica, sendo que $85,3 \%$ das propriedades faziam ordenha com "bezerro ao pé" e a média diária de produção por vaca era de 8,1 litros. 
Observa-se que as propriedades familiares avaliadas do município de Barroso apresentaram, comparativamente, maior especialização de produção do que as propriedades avaliadas nos demais diagnósticos citados, com característica predominância de ordenha mecanizada e suplementação alimentar nos sistemas de produção, além de mais elevadas produções diárias de leite tanto, por vaca quanto por propriedade.

Tabela 3. Caracterização dos sistemas de produção de leite nas 12 propriedades estudadas do município de Presidente Olegário - MG, em maio e junho de 2016.

\begin{tabular}{|c|c|c|c|}
\hline \multirow{2}{*}{ Questão } & \multirow{2}{*}{ Averiguação } & \multicolumn{2}{|c|}{ Quantidade } \\
\hline & & Total & $\%$ \\
\hline \multirow{2}{*}{ Sistema de criação } & Pasto & 4 & 33,33 \\
\hline & Semiconfinado & 8 & 66,67 \\
\hline \multirow{2}{*}{ Tipo de leite produzido } & Leite cru refrigerado & 11 & 91,67 \\
\hline & Leite cru & 1 & 8,33 \\
\hline \multirow{2}{*}{ Ordenha } & Bezerro ao pé & 9 & 75,00 \\
\hline & Sem bezerro ao pé & 3 & 25,00 \\
\hline \multirow{3}{*}{ Qual o tipo de ordenha } & Manual & 1 & 8,33 \\
\hline & Mecânica & 11 & 91,67 \\
\hline & Menos de 50 & 1 & 8,33 \\
\hline \multirow{3}{*}{ Volume diário de leite produzido } & De 100 a 149 & 2 & 16,67 \\
\hline & De 150 a 199 & 3 & 25,00 \\
\hline & 250 e mais & 6 & 50,00 \\
\hline \multirow{5}{*}{ Volume diário de leite vendido } & Menos de 50 & 1 & 8,33 \\
\hline & De 100 a 149 & 3 & 25,00 \\
\hline & De 150 a 199 & 2 & 16,67 \\
\hline & 250 e mais & 6 & 50,00 \\
\hline & Menos de 9 & 2 & 16,67 \\
\hline \multirow[t]{2}{*}{ Quantidade leite/vaca } & De 10 a 13 & 4 & 33,33 \\
\hline & 16 e mais & 6 & 50,00 \\
\hline
\end{tabular}

Quanto à alimentação de fêmeas da desmama até 12 meses, no período das águas, houve predomínio do uso de pastagem, sendo que quatro propriedades também forneciam silagem de milho (Zea mays), oito algum tipo de ração concentrada e uma suplementava com soro do leite. No período da seca, o uso de silagem de milho foi observado em 11 das propriedades, com oito ainda utilizando o pasto e também fornecendo algum tipo de concentrado. Para as novilhas com mais de 12 meses de idade, no período das águas, todas as propriedades utilizavam a pastagem como fonte de alimento volumoso e apenas duas faziam também suplementação com silagem de milho; sete forneciam algum tipo de ração concentrada (Tabela 4).

Já no período da seca, para essa categoria animal, o fornecimento de silagem de milho foi observado em 10 das propriedades e o pasto em sete, com oito fornecendo algum tipo de ração concentrada. Houve fornecimento de sal mineral para as novilhas em todas as propriedades ao longo de todo o ano (Tabela 4).
Conforme se observa na Tabela 5, em todas as propriedades os animais tinham acesso à água através de bebedouros; porém, a condição higiênica era, na maioria, regular ou ruim, o que pode comprometer a qualidade da água ingerida pelos animais, que nove dos produtores declararam como sendo regular. O dimensionamento foi considerado correto em 10 propriedades e a localização boa ou ótima, em nove. Apenas um produtor declarou não fazer escrituração zootécnica; e a idade à primeira cobertura, acontecia entre 18 a 20 meses em cinco propriedades. Quatro dos produtores vendiam suas novilhas antes da primeira cobertura, o que é comum em propriedades onde se usam touros não especializados para a produção leiteira com vistas à obtenção de animais aptos para recria e engorda na pecuária de corte, fato também observado por Marcatti Neto et al. (2007). Neste caso, os produtores precisam comprar novilhas para a reposição das vacas descartadas dos plantéis. $\mathrm{O}$ peso à primeira cobertura variou entre $270 \mathrm{a} 300 \mathrm{~kg}$ em todas as propriedades; valor inferior aos indica- 
dos em revisão feita por Borges et al. (2015), para animais leiteiros provenientes de cruzamentos europeu $\mathrm{x}$ zebu. Esses autores encontraram indicações de pesos variando entre 349 a $480 \mathrm{~kg}$ para a primeira cobertura com idade entre 21 e 26 meses, muito embora as novilhas mestiças provenientes desses cruzamentos apresentem puberdade entre 15 e 24 meses. Lopes et al. (2014) ressaltaram a importância de melhorar os índices reprodutivos, principalmente a idade ao primeiro parto, uma vez que este tem peso significativo no custo da fêmea para a reposição. Muito provavelmente, nas propriedades avaliadas neste estudo, as novilhas estejam sendo acasaladas com peso inferior ao indicado na literatura (Viégas, 2010), uma vez que os pesos adotados para a primeira cobrição são os indicados para animais puros da raça gir (Borges et al., 2015), o que pode comprometer o desenvolvimento final dos animais, bem como a sua produção futura. As novilhas, em nove das propriedades, não eram separadas em grupos em função de critérios zootécnicos.

Tabela 4. Caracterização da alimentação de fêmeas na fase de recria, após a demama, nas 12 propriedades estudadas do município de Presidente Olegário - MG, em maio e junho de 2016.

\begin{tabular}{|c|c|c|c|}
\hline \multirow{2}{*}{ Questão } & \multirow{2}{*}{ Averiguação } & \multicolumn{2}{|c|}{ Quantidade } \\
\hline & & Total & $\%$ \\
\hline \multirow{8}{*}{$\begin{array}{c}\text { Alimentos na época das águas - desmama até } 12 \\
\text { meses de idade }\end{array}$} & Pasto & 11 & 91,67 \\
\hline & Silagem de milho & 4 & 33,33 \\
\hline & Ração leite & 4 & 33,33 \\
\hline & Ração novilha & 3 & 25,00 \\
\hline & Ração crescimento & 1 & 8,33 \\
\hline & Mineral 2/1 & 3 & 25,00 \\
\hline & Sal mineral & 3 & 25,00 \\
\hline & Mineral recria & 1 & 8,33 \\
\hline \multirow{10}{*}{$\begin{array}{c}\text { Alimentos na época da seca - desmama até } 12 \\
\text { meses de idade }\end{array}$} & Soro de queijo & 1 & 8,33 \\
\hline & Pasto & 8 & 66,67 \\
\hline & Silagem de milho & 11 & 91,67 \\
\hline & Capim elefante & 1 & 8,33 \\
\hline & Ração leite & 5 & 41,67 \\
\hline & Ração novilha & 3 & 25,00 \\
\hline & Ração crescimento & 1 & 8,33 \\
\hline & Mineral 2/1 & 4 & 33,33 \\
\hline & Sal mineral & 3 & 25,00 \\
\hline & Mineral recria & 1 & 8,33 \\
\hline \multirow{7}{*}{$\begin{array}{l}\text { Alimentos na época das águas - acima de } 12 \text { meses } \\
\text { de idade }\end{array}$} & Pasto & 12 & 100,00 \\
\hline & Silagem de milho & 2 & 16,67 \\
\hline & Ração leite & 3 & 25,00 \\
\hline & Ração novilha & 3 & 25,00 \\
\hline & Ração recria & 1 & 8,33 \\
\hline & Mineral 2/1 & 3 & 25,00 \\
\hline & Sal mineral & 4 & 33,33 \\
\hline \multirow{10}{*}{$\begin{array}{l}\text { Alimentos na época da seca - acima de } 12 \text { meses de } \\
\text { idade }\end{array}$} & Mineral recria & 1 & 8,33 \\
\hline & Pasto & 7 & 58,33 \\
\hline & Silagem de milho & 10 & 83,33 \\
\hline & Capim elefante & 1 & 8,33 \\
\hline & Ração leite & 5 & 41,67 \\
\hline & Ração novilha & 3 & 25,00 \\
\hline & Ração recria & 1 & 8,33 \\
\hline & Mineral 2/1 & 3 & 25,00 \\
\hline & Sal mineral & 4 & 33,33 \\
\hline & Mineral recria & 1 & 8,33 \\
\hline
\end{tabular}


Tabela 5. Caracterização da infraestrutura, escrituração zootécnica e manejo reprodutivo nas 12 propriedades do município de Presidente Olegário - MG, em maio e junho de 2016.

\begin{tabular}{|c|c|c|c|}
\hline \multirow{2}{*}{ Questão } & \multirow{2}{*}{ Averiguação } & \multicolumn{2}{|c|}{ Quantidade } \\
\hline & & Total & $\%$ \\
\hline \multirow{4}{*}{ Condições higiênicas do bebedouro } & Ótima & 1 & 8,33 \\
\hline & Boa & 1 & 8,33 \\
\hline & Regular & 8 & 66,67 \\
\hline & Ruim & 2 & 16,67 \\
\hline \multirow{3}{*}{ Dimensionamento correto? } & Sim & 10 & 83,33 \\
\hline & Não & 2 & 16,67 \\
\hline & Ótima & 1 & 8,33 \\
\hline \multirow{4}{*}{ Localização do bebedouro } & Boa & 8 & 66,67 \\
\hline & Regular & 2 & 16,67 \\
\hline & Ruim & 1 & 8,33 \\
\hline & Ótima & 1 & 8,33 \\
\hline \multirow[t]{2}{*}{ Qualidade da água } & Boa & 2 & 16,67 \\
\hline & Regular & 9 & 75,00 \\
\hline \multirow{2}{*}{ Possui bóia? } & Sim & 9 & 75,00 \\
\hline & Não & 3 & 25,00 \\
\hline \multirow{4}{*}{ Realiza escrituração zootécnica? } & Sim & 11 & 91,67 \\
\hline & Não & 1 & 8,33 \\
\hline & Vende antes & 4 & 33,33 \\
\hline & 14 meses & 1 & 8,33 \\
\hline \multirow[t]{3}{*}{ Idade à primeira cobertura } & 18 a 20 meses & 5 & 41,67 \\
\hline & 24 meses & 1 & 8,33 \\
\hline & 36 meses & 1 & 8,33 \\
\hline \multirow[t]{2}{*}{ Peso à primeira cobertura } & 270 a $300 \mathrm{~kg}$ & 12 & 100,00 \\
\hline & Idade & 2 & 16,67 \\
\hline \multirow[t]{2}{*}{ Critério para agrupamento de recria } & Não separa & 9 & 75,00 \\
\hline & Outro & 1 & 8,33 \\
\hline
\end{tabular}

Com relação ao controle da sanidade das novilhas, apenas uma propriedade adotava calendário sanitário específico. Contudo, todos os proprietários realizavam a vacinação dos animais contra brucelose, raiva e febre aftosa, metade contra manqueira e outros cinco contra clostridioses diversas. O critério para controle de carrapatos utilizado em 11 das propriedades foi o grau de infestação; a taxa de infestação de carrapatos, moscas e bernes foi predominantemente, de média a alta. Apenas metade dos produtores fazia vermifugação de novilhas (Tabela 6).

Marcatti Neto et al. (2007) verificaram que 97,5\% dos produtores de leite no município de Barroso, MG, vacinavam contra febre aftosa (apesar de obrigatória) e raiva; e outros 76,9\% vacinavam contra brucelose. Em levantamento similar feito com produtores de leite no Agreste de Pernambuco, Monteiro et al. (2007) observaram que $95 \%$ dos produtores vacinavam contra febre aftosa e $56 \%$ contra brucelose. Em levantamento feito em região do Estado do Pará, Soares et al. (2013) relataram que todos os proprietários avaliados realizavam vacinação contra febre aftosa e $70 \%$ dos pequenos, $94 \%$ dos médios e $100 \%$ dos grandes produtores para brucelose. A terceira vacina mais empregada era contra clostridioses, sendo realizada por $60 \%$ dos pequenos, $94 \%$ dos médios e $100 \%$ dos grandes produtores. Esses autores também observaram que os tratamentos sanitários eram realizados sem critério por grande parte dos produtores, ou seja, quando apareciam infestações por ectoparasitas no rebanho. Os intervalos de aplicação nos animais eram realizados de seis em seis meses, juntamente com a vacinação contra febre aftosa, o que facilitava o manejo dos animais. Em geral a alternância de produtos para endoparasitas e ectoparasitas era feita sem critério ou orientação técnica. Borsanelli et al. (2014) observaram, inclusive, que produtores com produção diária inferior a 50 litros e/ou com menos de cinco anos na atividade tendem a vermifugar as vacas em lactação e não descartar o leite.

A falta de critérios técnicos e calendário sanitário específico é um problema comum aos pequenos produtores no Brasil (Borsanelli et al., 
2014), onde se enquandra a maior parte dos produtores familiares, e é uma das causas dos elevados índices de morbidade e mortalidade entre os animais jovens do plantel (Coelho, 2009). Isto prejudica o bom desempenho técnico e econômico das propriedades (Soares et al., 2013), afetando a taxa de reposição de fêmeas, e o desfrute, rejuvenescimento e melhoramento genético dos plantéis.

Tabela 6. Caracterização do controle sanitário da recria de bezerras nas 12 propriedades estudadas do município de Presidente Olegário - MG, em maio e junho de 2016.

\begin{tabular}{|c|c|c|c|}
\hline \multirow[b]{2}{*}{ Questão } & \multirow[b]{2}{*}{ Averiguação } & \multicolumn{2}{|c|}{ Quantidade } \\
\hline & & Total & $\%$ \\
\hline \multirow{2}{*}{ Existe um calendário sanitário? } & Sim & 1 & 8,33 \\
\hline & Não & 11 & 91,67 \\
\hline \multirow{4}{*}{ Quais vacinas são aplicadas regularmente } & Brucelose, Raiva, Febre aftosa & 12 & 100,00 \\
\hline & Clostridiose (manqueira) & 6 & 50,00 \\
\hline & Clostridioses diversas & 5 & 41,67 \\
\hline & Baixa & 1 & 8,33 \\
\hline \multirow{2}{*}{ Taxa de infestação de carrapatos em novilhas } & Média & 5 & 41,67 \\
\hline & Alta & 6 & 50,00 \\
\hline \multirow{3}{*}{ Critério para controle de carrapato } & Grau de infestação & 11 & 91,67 \\
\hline & De acordo com a bula & 1 & 8,33 \\
\hline & Baixa & 4 & 33,33 \\
\hline \multirow[t]{2}{*}{ Taxa de infestação de bernes em novilhas } & Média & 4 & 33,33 \\
\hline & Alta & 4 & 33,33 \\
\hline \multirow{2}{*}{ Taxa de infestação de mosca do chifre em novilhas } & Média & 4 & 33,33 \\
\hline & Alta & 6 & 66,67 \\
\hline \multirow{3}{*}{$\begin{array}{c}\text { Taxa de infestação de mosca doméstica em } \\
\text { novilhas }\end{array}$} & Baixa & 1 & 8,33 \\
\hline & Média & 5 & 41,67 \\
\hline & Alta & 6 & 50,00 \\
\hline \multirow{2}{*}{ É feita vermifugação? } & Sim & 6 & 50,00 \\
\hline & Não & 6 & 50,00 \\
\hline
\end{tabular}

\section{Conclusão}

A baixa escolaridade, o emprego quase que exclusivo de mão de obra familiar, a posse da terra por compra e a baixa participação de vacas em lactação nos plantéis são características comuns aos produtores familiares do município de Presidente Olegário.

A fase de recria nas propriedades apresenta diversas deficiências que se iniciam na desmama ou desaleitamento das bezerras e perpassam todo o período compreendido até a primeira cobertura das novilhas.

Apesar da oferta de alimentos volumosos e concentrados, a ausência de critérios técnicos para a divisão de lotes e alimentação suplementar das novilhas podem estar contribuindo significativamente para a perda de eficiência técnica e econômica nos rebanhos avaliados.

$\mathrm{O}$ peso e idade à primeira cobertura não são adequados à genética adotada nas propriedades, o que juntamente com a falta de correto manejo sanitário, pode vir a prejudicar a futura vida produtiva das fêmeas de reposição assim como o desfrute e o melhoramento genético dos plantéis.

\section{Conflito de Interesse}

Os autores declaram não existir conflito de interesse.

\section{Comitê de Ética}

A caracterização foi obtida de dadois provenientes de propriedades assistidas pela EMATER-MG, não sujeita a avaliação de comitê de ética. As propriedades e produtores foram mantidos anônimos.

\section{Agradecimentos}

Os autores agradecem à EMATER - MG, por ter possibilitado a realização desta pesquisa, e ao CNPq pela concessão de bolsa de produtividade ao terceiro autor.

\section{Referências}

Almeida Júnior, G.A.; Costa, C.; Carvalho, S.M.R.; Panichi, A.; Persichetti Júnior, P. Desempenho de bezerros holandeses alimentados após o desaleitamento com silagem de grãos úmidos ou grãos secos de 
milho ou sorgo. Revista Brasileira de Zootecnia, 37(1): 148-156, 2008.

Borges, A.M.; Martins, T.M.M.; Nunes, P.P.; Ruas, J.R.M. Reprodução de vacas mestiças: potencialidade e desafios. Revista Brasileira de Reprodução Animal, 39(1): 155-163, 2015.

Borsanelli, A.C.; Samara, S.I.; Ferraudo, A.S.; Dutra, I.S. Escolaridade e volume de produção têm associação com a percepção de risco de produtores de leite no uso de produtos veterinários. Pesquisa Veterinária Brasileira, 34(10): 981-989, 2014.

Campos, O.F. Bezerras: o futuro da propriedade. In Almeida Júnior, G.A.; Stradiotti Júnior, D.; Silva, E.C.G.; Andrade, M.A.N.; Almeida, M.I.V.; Cóser, A.C. Avanços tecnológicos na bovinocultura de leite. Alegre: CAUFES, 2012. p.142-156.

Climate-Data.Org. Dados climáticos para cidades mundiais. Gráfico climático. Disponível em: <http://pt.climatedata.org/location/176030/>. Acesso em: 06 dez. 2015.

Coelho, S.G. Desafios na criação e saúde de bezerros. Ciência Animal Brasileira, 10(1): 1-16, 2009.

Empresa de Assistência Técnica e Extensão Rural do Estado de Minas Gerais - EMATER-MG. Sistema safra pecuária. Presidente Olegário: EMATER-MG, 2015.

Instituto Brasileiro de Geografia e Estatística IBGE. Produção da pecuária municipal. Rio de Janeiro: IBGE, 2014. Disponível em: $<$ http://www.cidades.ibge.gov.br/xtras/temas. php?lang

$=\& \operatorname{codmun}=315340 \&$ idtema $=147 \&$ search $=$ minas-gerais|presidente-olegario|pecuaria2014>. Acesso em: 06 dez. 2015.

Lopes, M.A.; Lima, A.L.R.; Carvalho, F.M.; Reis, R.P.; Santos, I.C.; Saraiva, F.H. Controle gerencial e estudo da rentabilidade de sistemas de produção de leite na região de Lavras (MG). Ciência e Agrotecnologia, 28(4): 883892, 2004.

Lopes, M. A.; Demeu, F. A.; Costa G. M.; Rocha, C. M. B. M.; Abreu, L. R.; Santos, G.; Franco
Neto, A. Influência da contagem de células somáticas no impacto econômico da mastite em rebanhos bovinos leiteiros. Arquivos do Instituto Biológico, 78(4): 493-499, 2011.

Lopes, M.A.; Reis, E.M.B.; Ferrazza, R. A. Formulário de diagnóstico da propriedade leiteira. Lavras: UFLA, 19. p. 2016.

Marcatti Neto, A.; Gonçalves Filho, A.F.; Godoy, M.; Amaral, R.; Azevedo, N.A.; Silva, J.B. Diagnóstico da pecuária leiteira do município de Barroso. Belo Horizonte: EPAMIG, 2007, 24p.

Mello, M.A.; Abramovay, R.; Silvestro, M.L.; Dorigon, C.; Ferrari, D.F.; Testa, V.M. Sucessão hereditária e reprodução social da agricultura familiar. Agricultura em São Paulo, 50(1): 11-24, 2003.

Monteiro, A.A.; Tamanini, R.; Silva, L.C.C.; Mattos, M.R.; Magnani, D.F.; Ovidio, L.; Nero, L.A.; Barros, M.A.F.; Pires, E.M.F.; Paquereau, B.P.D.; Beloti, V. Características da produção leiteira da região do agreste do estado de Pernambuco, Brasil. Semina: Ciências Agrárias, 28(4): 665-674, 2007.

Oliveira, T.B.A.; Figueiredo, R.S.; Oliveira, M.W.; Nascif, C. Índices técnicos e rentabilidade da pecuária leiteira. Scientia Agricola, 58(4): 687-692, 2001.

Santos, G.; Lopes, M.A. Custos de produção de fêmeas bovinas leiteiras do nascimento ao primeiro parto. Ciência Animal Brasileira, 15(1): 11-19, 2014.

Soares, S.O.; Oaigen, R.P.; Barbosa, J.D.; Oliveira, C.M.C.; Albernaz, T.T.; Domingues, F.N.; Maia, J.T.S.; Christmann, C.M. Perfil dos produtores de leite e caracterização técnica das propriedades leiteiras dos municípios de Rondon do Pará e Abel Figueiredo, Estado do Pará. Veterinária em Foco, 10(2): 159-168, 2013.

Viégas, J. Manejo de novilhas leiteiras, em busca da eficiência técnica. In: Santos, G.T.; Massuda, E.M.; Kazama, D.C.S.; Jobim, C.C.; Branco, A.F. Bovinocultura leiteira: bases zootécnicas, fisiológicas e de produção. Maringá: EDUEM, 2010. p.79-107. 